\title{
Cardiac myxoma: Simplifying a "complex" case
}

\author{
Sahar A. Saddoughi, MD, PhD, ${ }^{\mathrm{a}}$ Joseph J. Maleszewski, MD, ${ }^{\mathrm{b}}$ and Hartzell V. Schaff, MD ${ }^{\mathrm{a}}$
}

\author{
From the Departments of ${ }^{\mathrm{a}}$ Cardiovascular Surgery and ${ }^{\mathrm{b}}$ Pathology, Mayo Clinic, Rochester, Minn. \\ Disclosures: Authors have nothing to disclose with regard to commercial support. \\ Received for publication June 8, 2016; revisions received July 11, 2016; accepted for publication July 12, 2016 ; \\ available ahead of print Aug 25, 2016. \\ Address for reprints: Hartzell V. Schaff, MD, Department of Cardiovascular Surgery, Mayo Clinic, 200 First St \\ SW, Rochester, MN 55905 (E-mail: schaff.hartzell@mayo.edu). \\ J Thorac Cardiovasc Surg 2016;152:1439-40 \\ $0022-5223 / \$ 36.00$ \\ Copyright (c) 2016 by The American Association for Thoracic Surgery \\ http://dx.doi.org/10.1016/j.jtcvs.2016.07.061
}

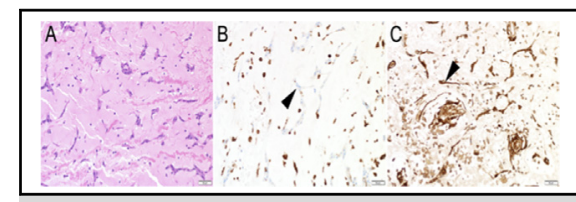

PRKAR1A staining of the myxoma cells in syndromic and nonsyndromic myxoma.

\section{Central Message}

There are no gross or histologic tumor features distinguishing syndromic and nonsyndromic myxomas. IHC staining of PRKAR1A has proved useful in identifying tumors at increased risk of being syndromic.

See Editorial Commentary page 1440.
Cardiac myxoma is a benign neoplasm that can present as an isolated mass (nonsyndromic) or in association with Carney complex (syndromic). Carney complex is a rare autosomal dominant condition caused by inactivating mutations of the tumor suppressor gene PRKARIA and characterized by spotty skin pigmentation, myxomas (cardiac and extracardiac), and endocrinopathy. There are no gross or histologic tumor features that distinguish syndromic and nonsyndromic myxomas (Figure 1 and Video 1). Recently, immunohistochemical staining of

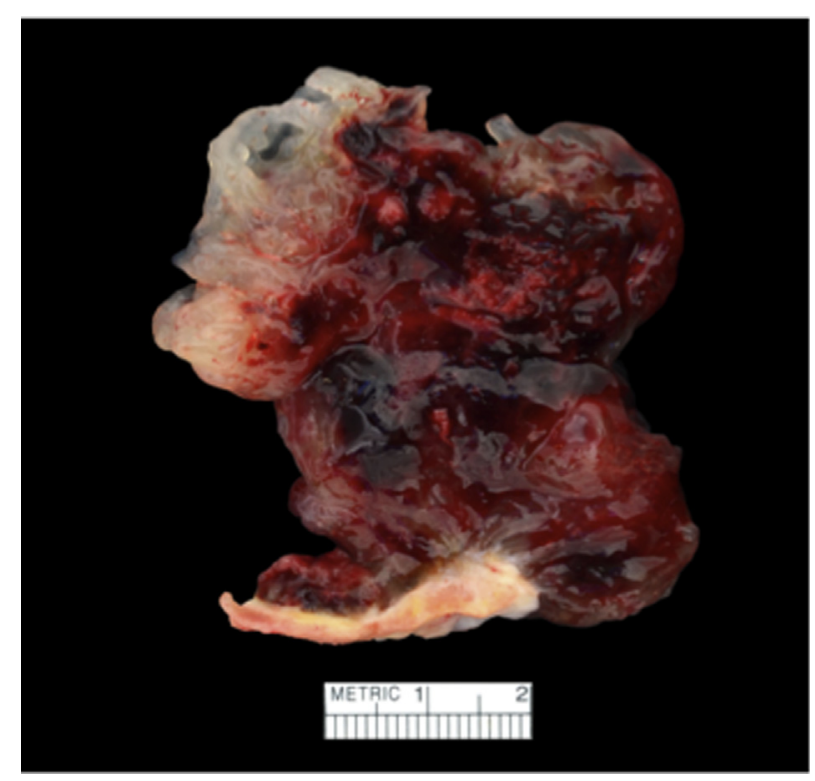

FIGURE 1. Gross specimen of the left atrial myxoma.
PRKARIA has proven utility in helping to identify patients at increased risk of having syndromic disease. ${ }^{1}$ Normal myocardium and nonsyndromic myxomas stain with a mouse monoclonal antibody directed against PRKARIA, whereas those in the setting of Carney complex reliably lack such staining (Figure 2). Lack of PRKARIA staining is $100 \%$ sensitive for Carney complex myxoma but is only $68 \%$ specific, because a small subset of nonsyndromic tumors may also have abnormal PRKARIA expression. Because of the rare nature of Carney complex, we believe that this immunohistochemical staining allows for an easy, inexpensive method of distinguishing those patients who may need further (ie, molecular genetic) testing.

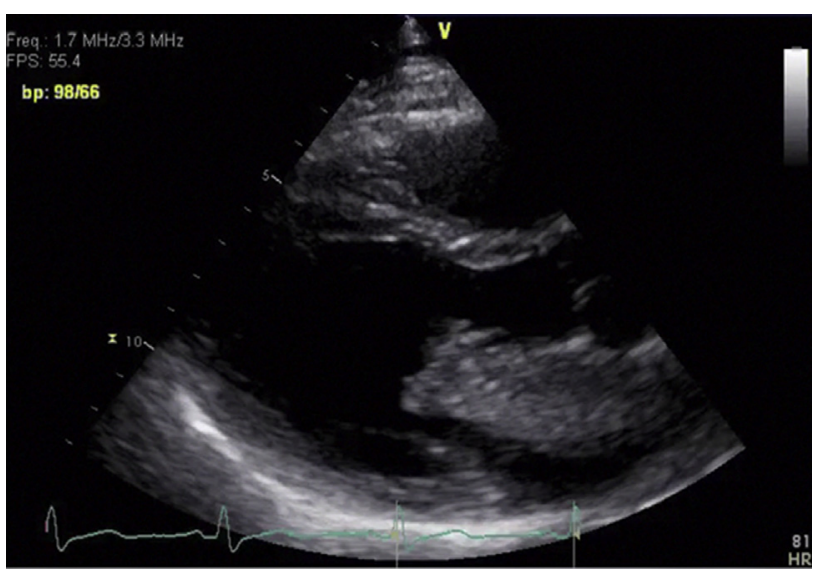

VIDEO 1. Preoperative echocardiogram demonstrating left atrial myxoma. Video available at http://www.jtcvsonline.org/article/S0022-5223 (16)30882-0/addons. 

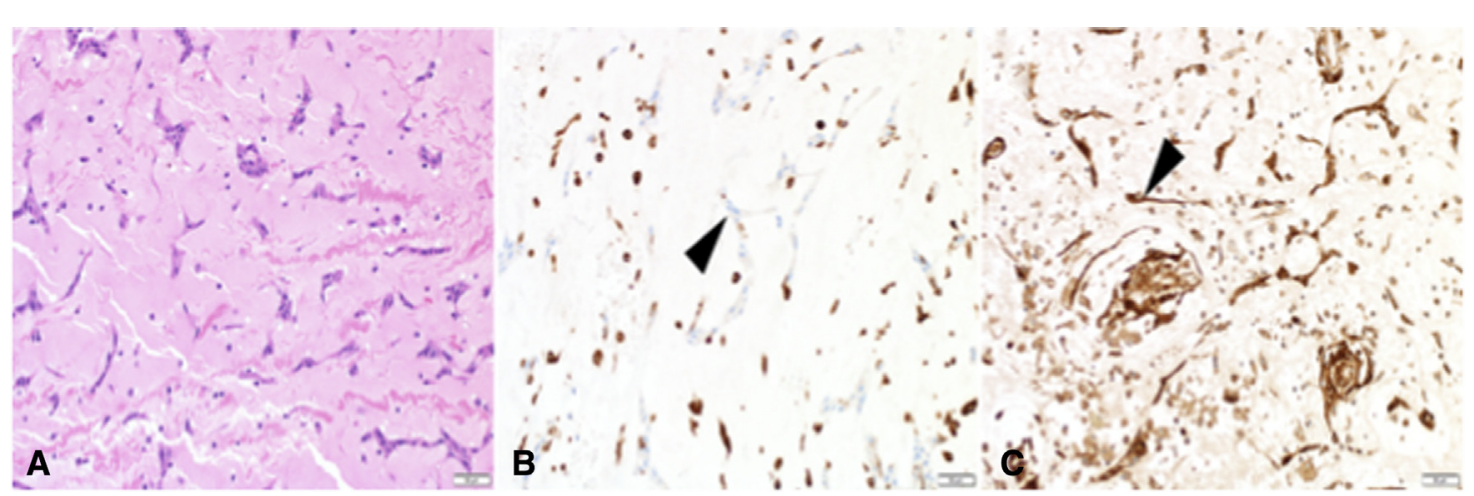

FIGURE 2. Histopathologic staining. A, Myxoma cells populating a myxoid background (hematoxylin and eosin stain). B, Lack of PRKARIA staining in this case. Black arrow indicates myxoma cells. C, PRKARlA staining of the myxoma cells (black arrow) in a nonsyndromic myxoma (for comparison).

\section{Reference}

1. Maleszewski JJ, Larsen BT, Kip NS, Castonguay MC, Edwards WD,

Carney JA, et al. PRKARIA in the development of cardiac myxoma: a study of 110 cases including isolated and syndromic tumors. Am J Surg Pathol. 2014;38:1079-87.

\title{
EDITORIAL COMMENTARY
}

\section{Timely screening for Carney complex and PRKAR1A gene mutations}

\author{
Jun Feng, MD, PhD
}

\footnotetext{
From the Division of Cardiothoracic Surgery, Cardiovascular Research Center, Rhode Island Hospital, Alpert Medical School of Brown University, Providence, RI

Disclosures: Author has nothing to disclose with regard to commercial support.

Received for publication July 25, 2016; accepted for publication July 26, 2016; available ahead of print Aug 24, 2016.

Address for reprints: Jun Feng, MD, PhD, Division of Cardiothoracic Surgery, Cardiovascular Research Center, Rhode Island Hospital, Coro West, Room 5.229, 1 Hoppin St, Providence, RI 02903 (E-mail: jfeng @ lifesapn. org).

J Thorac Cardiovasc Surg 2016;152:1440-1

$0022-5223 / \$ 36.00$

Copyright (c) 2016 by The American Association for Thoracic Surgery

http://dx.doi.org/10.1016/j.jtcvs.2016.07.060
}

"Modify, simplify, and apply."

$$
\text { -Denton Cooley, MD }
$$

Carney complex (also known as "myxoma syndrome") is a rare autosomal dominant multineoplasia syndrome, which consists of myxomas in different locations, spotty skin pigmentation, and endocrine overactivity. ${ }^{1}$ Cardiac myxomas are the second most frequent manifestations of Carney complex. The majority of cardiac myxomas are benign; however, they may be recurrent with significant morbidity and mortality. ${ }^{1,2}$ Therefore, patients presenting with cardiac myxoma generally are considered to be surgical emergencies, and complete surgical resection

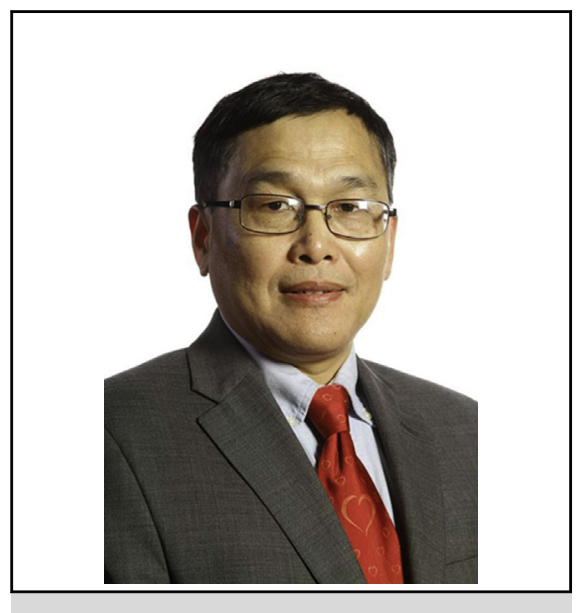

Jun Feng, MD, PhD

Central Message

Immunohistochemistry staining of PRKAR1A may be useful as a simple screening method for identifying patients with Carney complex.

See Article page 1439 